\title{
Microsurgical Resection of Cerebellopontine Angle Meningioma
}

\author{
Duarte N. C. Cândido ${ }^{1}$ Gustavo A. R. Passos ${ }^{1}$ Marcio S. Rassi ${ }^{1}$ Jean Gonçalves de Oliveira ${ }^{2,3}$ \\ Luis A. B. Borba ${ }^{1,4}$
}
${ }^{1}$ Department of Neurosurgery, Hospital Universitário Evangélico de Curitiba, Curitiba, Paraná, Brazil
2 Division of Neurosurgery, Department of Surgery, Santa Casa de São Paulo School of Medical Sciences (FCMSCSP), Hospital Beneficência Portuguesa de São Paulo, São Paulo, Brazil
${ }^{3}$ Division of Cerebrovascular and Skull Base surgery, Center of Neurology and Neurosurgery Associates (CENNA), Hospital Beneficência Portuguesa de São Paulo, São Paulo, Brazil
${ }^{4}$ Department of Neurosurgery, Federal University of Parana, Curitiba, Paraná, Brazil

\author{
Address for correspondence Luis A. B. Borba, MD, PhD, IFAANS, Rua \\ Gen. Carneiro, 181-Alto da Glória, Curitiba, Paraná, Brazil 80060-900 \\ (e-mail: luisborba@me.com).
}

J Neurol Surg B 2019;80(suppl S3):S305-S307.

\begin{abstract}
Keywords

- cerebellopontine angle

- meningioma

- skull base

- tumor

Meningiomas of the cerebellopontine angle (CPA) are the second most frequent lesions related to this region (around $10-15 \%),{ }^{1}$ being the vestibular schwannomas the first (around $85 \%$ ). This lesions arise from the dura of the petrosal surface of the temporal bone, lateral to the trigeminal nerve (- Fig. 1). Variable attachment sites and directions of growth make different clinical presentations and operative challenges. This pathologies can be classified accordingly to they're extension related to the internal acoustic meatus in: postmeatal, premeatal, and large meningiomas with pre- and postmeatal extension (-Fig. 2). We present an operative video performed by the senior author (L.A.B.B.). A 64-year-old woman with 3 months of complaint of left facial pain on the V2 territory of the trigeminal nerve and diplopia secondary to $\mathrm{VI}$ nerve paresis. Magnetic resonance imaging (MRI) scans demonstrated a large homogeneous enhancing lesion at the left CPA, extending pre- and postmeatal and from the tentorium cerebeli to the jugular foramen region, highly suggestive of CPA meningioma. Surgery was offered to the patient as a first option. In our point of view, neurophysiological monitoring with somatosensory and motor evoked potentials is mandatory while dealing with such large tumors around the CPA. The surgery was performed after a standard retrosigmoid craniotomy, with careful dissection and debulking while devascularizing the tumor from its petrosal attachment. Near-total resection was achieved and the patient had a remarkable postoperative outcome with improvement of the diplopia and facial pain with preservation of VII and VIII nerves function. The pathology demonstrated a grade 1 meningioma.

The link to the video can be found at: https://youtu.be/UVVyEhq8Fu0.
\end{abstract}

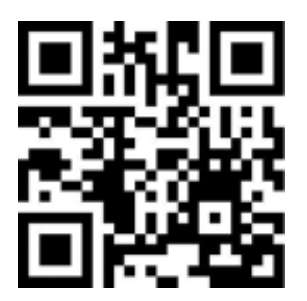

received

May 30, 2018 accepted after revision November 11, 2018 published online February 18, 2019

www.thieme.com/skullbasevideos

www.thieme.com/jnlsbvideos

DOI https://doi.org/

10.1055/s-0038-1677493. ISSN 2193-6331.
๑) 2019 Georg Thieme Verlag KG
Stuttgart · New York

License terms

(c) $(1) \ominus$ (\$) 


\section{Financial Support}

The authors had no financial support to disclose.

\section{Conflict of Interest}

None declared.

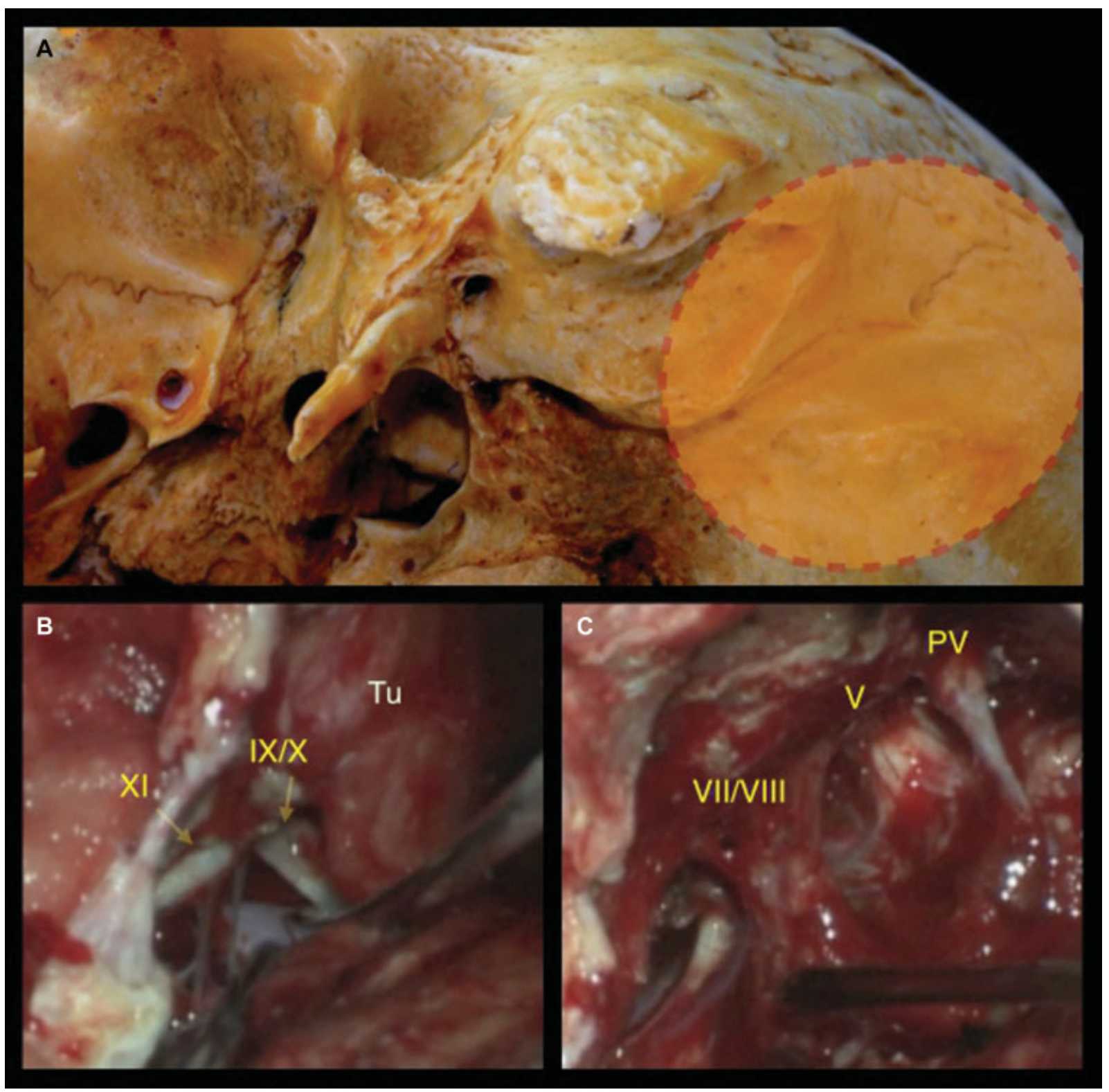

Fig. 1 (A) Osseous demonstration of the region involved in the retrosigmoid approach; (B) identification of the lower cranial nerves; (C) preservation of the VII/VIII nerves complex, $\mathrm{V}$ nerves and Petrosal Vein (PV) after tumor resection. Tu, tumor. 


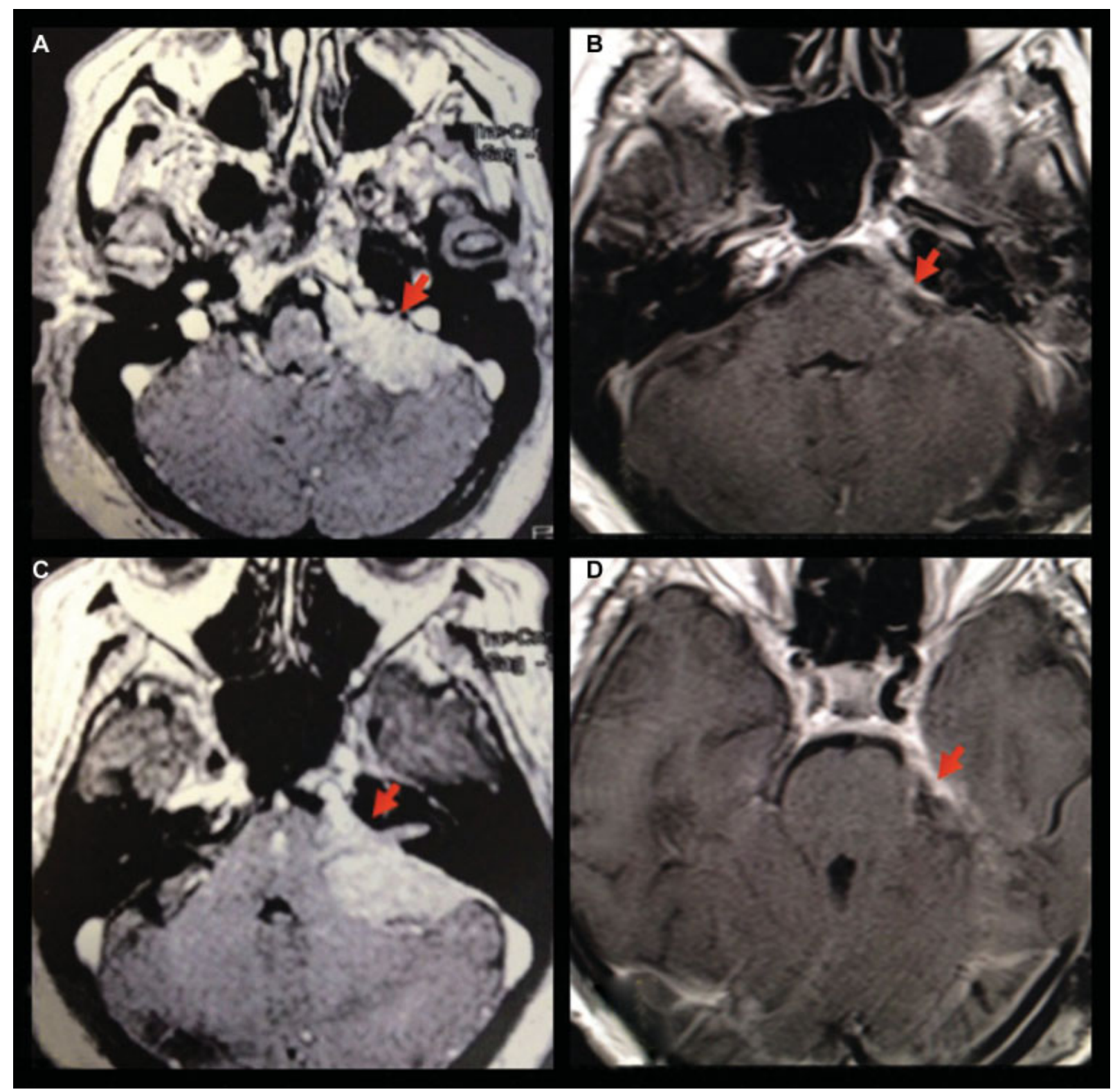

Fig. 2 (A and B) Preoperative MRI demonstrating the tumor extension to the pre- and postmeatal region of the left cerebellopontine angle; (C and D) postoperative MRI with complete tumor removal. MRI, magnetic resonance imaging.

\section{Reference}

1 Sammii M, Gerganov VM. Cerebellopontine angle meningiomas. In: Al-Mefty O, DeMonte F, McDermott M, eds. Al-Mefty's Meningiomas. 2nd ed. New York: Thieme; 2011:262-269 